\title{
Helmintic infections in water buffaloes on Italian farms: a spatial analysis
}

\author{
Laura Rinaldi ${ }^{1}$, Vincenzo Musella ${ }^{2}$, Vincenzo Veneziano ${ }^{1}$, Renato U. Condoleo ${ }^{3}$, \\ Giuseppe Cringoli ${ }^{1}$ \\ ${ }^{1}$ Department of Pathology and Animal Health, University of Naples "Federico II", Naples, Italy; \\ ${ }^{2}$ Department of Clinical and Experimental Medicine, University of Catanzaro Magna Graecia, Catanzaro, \\ Italy; ${ }^{3}$ Istituto Zooprofilattico Sperimentale del Lazio e della Toscana, Section of Latina, Italy
}

\begin{abstract}
The present paper reports the results of a cross-sectional survey aimed at obtaining up-to-date information on the spatial distribution of different groups and/or species of helminths in water buffaloes from central Italy. Geographical information systems (GIS) and spatial analysis were used to plan the sampling procedures, to display the results as maps and to detect spatial clusters of helminths in the study area. The survey was conducted on 127 water buffalo farms, which were selected in the study area using a grid sampling approach, followed by proportional allocation. Faecal samples $(\mathrm{n} .=1,883)$ collected from the 127 farms were examined using the Flotac dual technique. Gastrointestinal strongyles were the most frequent helminths $(33.1 \%)$ on the tested farms, followed by the liver fluke Fasciola hepatica $(7.1 \%)$, the rumen fluke Calicophoron daubneyi $(7.1 \%)$, the nematode Strongyloides spp. (3.1\%), the lancet liver fluke Dicrocoelium dendriticum (2.4\%) and the tapeworm Moniezia spp. (2.4\%). In order to display the spatial distribution of the various helminths detected on the water buffalo farms (used as epidemiological unit in our study), point maps were drawn within the GIS. In addition, for each helminth, clustering of test-positive farms were investigated based on location determined by exact coordinates. Using spatial scan statistic, spatial clusters were found for the flukes F. hepatica and C. daubneyi and the cestode Moniezia spp.; these findings are consistent with the life cycle of these parasites, which have strong environmental determinants. In conclusion, the present study demonstrated that, with the appropriate survey-based data at hand, GIS is a useful tool to study epidemiological patterns of infections in veterinary health, in particular in water buffaloes.
\end{abstract}

Keywords: helminths, water buffalo, buffalo farming, geographical information systems, spatial analysis, Italy.

\section{Introduction}

The water buffalo (Bubalus bubalis) is a ruminant species important in the economy of several countries, including Brazil, China, India, Vietnam and some regions of central and southern Italy. Indeed, in Italy, the Mediterranean buffalo breed produces high

\footnotetext{
Corresponding author:

Giuseppe Cringoli

Dipartimento di Patologia e Sanità Animale

Facoltà di Medicina Veterinaria

Università degli Studi di Napoli "Federico II"

Via della Veterinaria, 1- 80137 Napoli, Italy

Tel. +39081 2536283; Fax +39081 2536282

E-mail: cringoli@unina.it

website: www.parassitologia.unina.it
}

quality milk employed for production of "mozzarella", a fresh cheese with a protected designation of origin (PDO) according to EU legislation (CEE N 1107, 12 June 1996) (Romano et al., 2001). Buffalo milk is receiving increasing research interest and investment in various countries, owing mainly to its attractive nutrient content (Amarjit and Toshihiko, 2003). It is ranked second in the world after cow's milk, accounting for more than $12 \%$ of the world's milk production (CNIEL, 2002). Considering the health implications and the economic potential of water buffaloes, the issue of investigating parasitic infections buffaloes is of considerable relevance (Rinaldi et al., 2007; Veneziano et al., 2007).

Helminth infections of water buffaloes are consid- 
ered common in tropical and sub-tropical countries where they cause huge economic losses as a consequence of deaths of infected animals, reduced rates of weight gains and the condemnation of infected organs after slaughter (Liu et al., 2009). Some helminths infecting buffaloes primarily are also transmissible (directly or indirectly) to humans where they can cause significant clinical disease, such as schistosomiasis (in China and the Philippines), cycstic echinococcosis, and fasciolosis (Cringoli et al., 2007; Liu et al., 2009).

As regard to Italy, in the past (more than 30 years ago), when the farm management was characterized by extensive breeding on pastures, a group of water buffaloes without helminths did not exist. The progressive transformation of water buffalo farms (intensive breeding techniques and constant supplies of concentrated and/or stored forages), together with the regular use of anthelminthic treatments, could be significant factors contributing to such decrease of helminth infections in water buffalo farms in Italy.

However, information on the presence and distribution of helminths in water buffaloes from Italy were conducted in the 1970s (e.g. Rivellini et al., 1972), when buffaloes were mainly bred on pasture and when anthelmintic treatments were not widely used.

The present paper reports the results of a crosssectional survey aimed at obtaining up-to-date information on the spatial distribution of helminths in water buffaloes from central Italy, where the farm management system is nowadays characterized by intensive breeding techniques. Different geographical information system (GIS) tools were used to plan the sampling procedures, to display the results as maps and to detect spatial clusters of helminths in water buffaloes in the study area.

\section{Materials and methods}

\section{Study area}

The survey was conducted in the Lazio region of central Italy, in 20 contiguous municipalities (surface area $\sim 1,250 \mathrm{~km}^{2}$ ), located in the provinces of Latina and
Frosinone $\left(41^{\circ} 27^{\prime}-41^{\circ} 53^{\prime} \mathrm{N}\right.$ and $\left.12^{\circ} 93^{\prime}-13^{\circ} 47^{\prime} \mathrm{E}\right)$. In this region, $18 \%$ of all Italian water buffaloes are bred.

This area is mainly flat, though in small parts both hilly and mountainous, and extends from 0 to $1,500 \mathrm{~m}$ above sea level. There are some lakes and many small rivers. The climate is typically Mediterranean with dry summers and rainy winters.

\section{GIS data-layers}

A GIS was constructed utilizing as data-layers the topographic base map (at the scale 1:25,000; source: Italian Geographic Military Institute) and digital aerial photographs (at $1.0-\mathrm{m}$ resolution; source: Cartographic Office of the Lazio region) of the study area.

Before conducting the parasitological survey, all the buffalo farms located in the study area were georeferenced on aerial photographs within the GIS. This typology for geo-referencing appeared to be more precise and cheaper than collecting points manually with a global positioning system (GPS) receiver (Cringoli et al., 2005, 2007; Rinaldi et al., 2006). All GIS databases were developed using ArcGIS 9.2 GIS software (ESRI, Redlands, CA, USA).

\section{Sample size and distribution}

The survey was conducted on 127 water buffalo farms. This sample size was calculated using the formula proposed by Thrusfield (1995) inserting the following values: study population (531 buffalo farms), expected prevalence of helminth infections $(8 \%)$, confidence interval $(95 \%)$ and desired absolute precision $(5 \%)$. The 127 farms that comprised the sample were selected using a grid approach (Rinaldi et al., 2006) followed by proportional allocation. For this purpose, a grid representing quadrants of $5 \times 5 \mathrm{~km}$ was overlaid on the study area within the GIS. As a result, the study area was divided into equal quadrants, and the 127 farms were chosen to be proportionally allocated at the quadrant level (Thrusfield, 1995), i.e. the number of farms sampled in each quadrant was proportional to the total number of 
study subjects in that quadrant. Within these numerical constraints, the specific farm(s) to be studied in each quadrant were randomly selected among all the farms geo-referenced into the GIS database.

\section{Faecal samples and copromicroscopic examinations}

In each farm, the number of buffaloes tested (adults, heifer/steers and calves) ranged from 9 to 21 based on the number of animals on the farm. The total number of faecal samples collected from the 127 farms was 1,883. Copromicroscopic examinations were performed using the Flotac dual technique (Cringoli, 2006; FLOTAC ${ }^{\circledR}$ Manual - Flotac techniques - Herbivores, 2009), based upon the use of two different flotation solutions, that have complementary specific gravity, and used in parallel on the same faecal sample. In particular, a sucrose-based solution (sucrose plus potassium iodomercurate; specific gravity (s.g.) $=1.25$ ) was used in order to detect nematode and cestoda eggs, and a zinc suphate-based solution (zinc sulphate heptahydrate plus potassium iodomercurate; s.g. $=1.45$ ) was used in order to detect trematode eggs (Cringoli et al., 2004).

The analytic sensitivity of the Flotac dual technique was 2 eggs per gram of faeces (EPG).

\section{Mapping and clustering}

In order to display the spatial distribution of the various helminths detected in the water buffa- lo farms (used as epidemiological units in our study), point maps were drawn within the GIS.

For each helminth, clustering of test-positive farms was investigated based on location determined by exact coordinates and using the spatial scan statistic as described by Kulldorff (1997). In particular, SaTScan ${ }^{\mathrm{TM}}$ (Information Management Services, Inc.) version 7.0 (www.satscan.org, 2006) was used. The testing was performed using a Bernoulli model (Kulldorff, 1997) where the test-positive farms were considered cases and test-negative farms were considered controls (Frössling et al., 2008). The maximum cluster sizes tested were $50 \%$ of the population at risk and both circular and elliptic cluster shapes were applied. Significance of clusters was tested using the Monte Carlo hypothesis testing (9,999 permutations).

\section{Results}

The results of the copromicroscopic survey, both on farms and on animals, are summarized in Table 1. Gastrointestinal (GI) strongyles were the most frequent helminths $(33.1 \%)$ on the tested farms, followed by the liver fluke Fasciola hepatica $(7.1 \%)$, the rumen fluke Calicophoron daubneyi $(7.1 \%)$, Strongyloides spp. nematodes $(3.1 \%)$, the lancet liver fluke Dicrocoelium dendriticum $(2.4 \%)$, and the tapeworm Moniezia spp. $(2.4 \%)$.

Table 1. The absolute number of positives, their distribution percentage-wise and the number of eggs per gram of faeces (EPG) found in water buffaloes (farms and individual animals) tested for helminths in the Lazio region of central Italy.

\begin{tabular}{|c|c|c|c|c|c|c|c|c|}
\hline \multirow{2}{*}{$\begin{array}{l}\text { Species and/or group of } \\
\text { helminths detected in the } \\
\text { water buffaloes }\end{array}$} & \multicolumn{3}{|c|}{$\begin{array}{c}\text { Farm positivity } \\
(\mathrm{n} . \text { examined }=127)\end{array}$} & \multicolumn{3}{|c|}{$\begin{array}{c}\text { Animal positivity } \\
\text { (n. } \text { examined }=1,883 \text { ) }\end{array}$} & \multicolumn{2}{|c|}{$\begin{array}{c}\text { EPG } \\
\text { on positive farms }\end{array}$} \\
\hline & No. pos. & $\%$ & $95 \% \mathrm{CI}^{*}$ & No. pos. & $\%$ & $95 \% \mathrm{CI}^{*}$ & $\min$ & $\max$ \\
\hline Gastrointestinal strongyles & 42 & 33.1 & $25.1-42.0$ & 101 & 5.4 & $4.1-6.5$ & 2 & 150 \\
\hline Fasciola hepatica & 9 & 7.1 & $3.5-13.4$ & 25 & 1.3 & $0.9-2.0$ & 2 & 28 \\
\hline Calicophoron daubneyi & 9 & 7.1 & $3.5-13.4$ & 39 & 2.1 & $1.5-2.8$ & 2 & 64 \\
\hline Strongyloides spp. & 4 & 3.1 & $1.0-8.4$ & 7 & 0.4 & $0.2-0.8$ & 2 & 50 \\
\hline Dicrocoelium dendriticum & 3 & 2.4 & $0.6-7.3$ & 3 & 0.2 & $0.0-0.5$ & 2 & 32 \\
\hline Moniezia spp. & 3 & 2.4 & $0.6-7.3$ & 4 & 0.2 & $0.1-0.6$ & n.a. & n.a. \\
\hline
\end{tabular}

* CI = confidence interval; n.a. = not assessed. 
a)

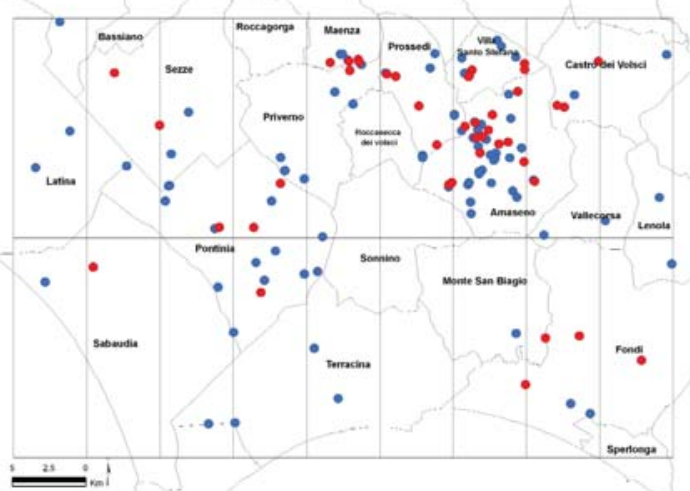

b)

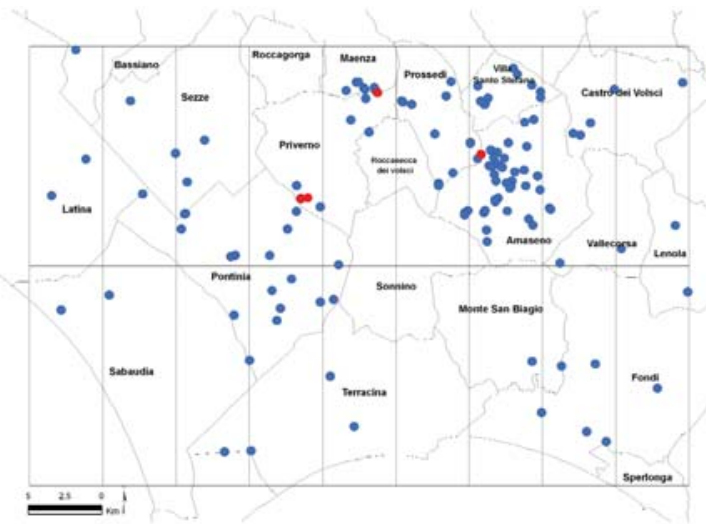

c)

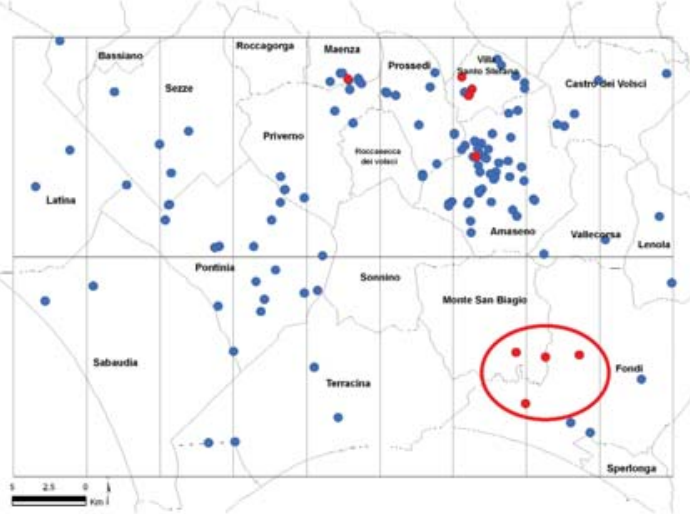

d)

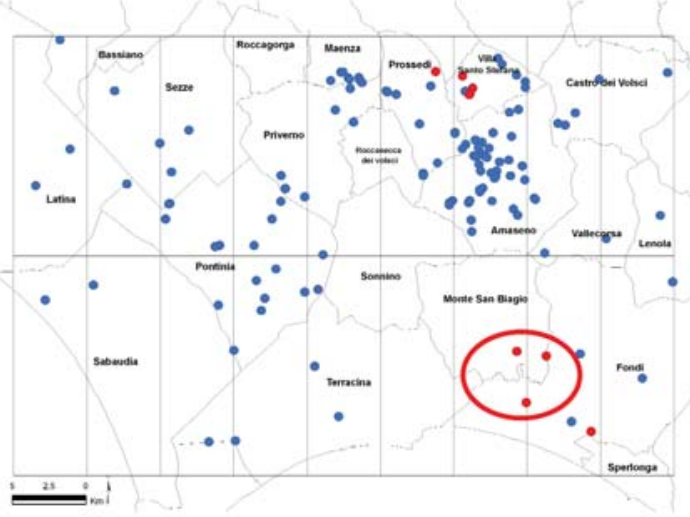

e)

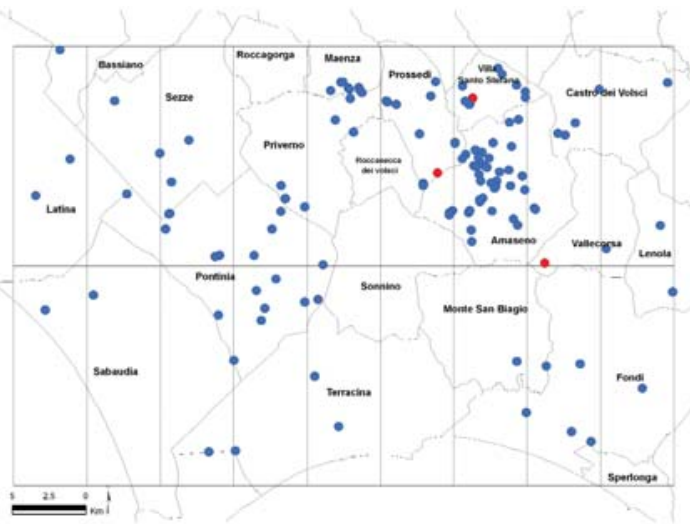

f)

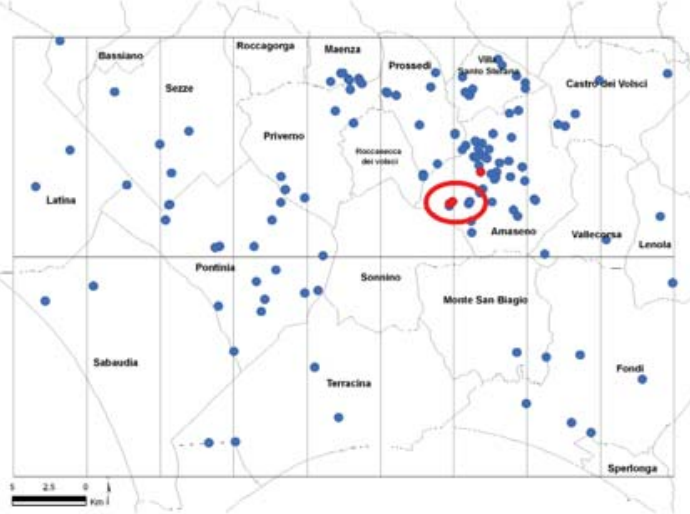

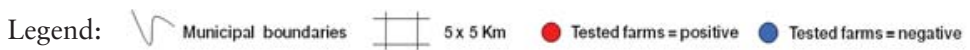

Fig. 1. Point maps of helminths in water buffalo farms from the Lazio region of central Italy: a) gastrointestinal strongyles; b) Strongyloides spp.; c) Fasciola hepatica; d) Calicophoron daubneyi; e) Dicrocoelium dentriticum; f) Moniezia spp. 
The spatial distribution of each helminth found at the water buffalo farms in the study area is shown in the point distribution maps (Figs. 1a-f).

The results of the spatial scan statistic analyses showed one cluster of positive farms at the same location, for both F. hepatica $(\mathrm{P}=0.001)$ (Fig. 1c) and C. daubneyi ( $\mathrm{P}=0.014$ ) (Fig. $1 \mathrm{~d}$ ). Another cluster of positive farms was detected for the cestode Moniezia spp. ( $\mathrm{P}=0.041)$ (Fig. 1f) . No clusters of positive farms were found for any of the other helminths detected $(\mathrm{P}>0.05)$.

\section{Discussion}

The present study reports the up-to-date situation of the spatial distribution of helminths in water buffalo farms of central Italy, whose management is nowadays characterized by intensive breeding. Indeed, water buffaloes are used as dairy animals in Italy; they are an important economic resource for the industry of milk and milk-derived products. Due to their high economic value and strong enforcement of the Italian veterinary surveillance law, water buffalo farms are very well organized (Cringoli et al., 2007) and thus helminth infections are considered overcome, which is partially confirmed by the results of the present study.

The findings of the present cross-sectional survey showed helminth prevalence values quite low both on farms and on individual animals; these findings are very similar to those reported by Cringoli et al. (1995) in water buffaloes from the Caserta province of southern Italy. The current intensive buffalo breeding in Italy could be responsible of these low values for prevalence for helminths, contrasting with the high prevalence values for intestinal protozoa as Eimeria spp., Giardia spp. and Cryptosporidium spp. (Rinaldi et al., 2007) and arthropoda as lice (Veneziano et al., 2007).

The above-described scenario of helminths in water buffaloes from Italy is different compared to the situation in other settings, for example in the Hunan province of China, where the individual prevalence of trematodes and nematodes in buf- faloes is still very high, e.g. $61.8 \%$ for GI strongyles and $44.7 \%$ for F. hepatica, as recently detected in an abattoir-survey by Liu et al. (2009).

In the present study, the use of GIS tools was instrumental in order to plan the sampling procedures, to show the results with point maps and to detect clusters of distribution of each helminth detected. The prior geo-referencing of the total buffalo farms present in the study area allowed us to use the grid approach followed by proportional allocation as territorial sampling procedure; this approach warrants a territorial distribution of the sample consistent with the territorial distribution of the study population. The use of grids $(5 \times 5 \mathrm{~km}$ in the present study) is considered very useful in order to produce usable point density maps (Cringoli et al., 2002) of parasites in ruminants without the need for further interpolation or extrapolation (Hendrickx et al., 2004).

The similar prevalence values $(7.1 \%$ on farms $)$ and the similar clustered spatial distribution of the liver and rumen flukes (i.e. F. hepatica and C. daubneyi) in the study area are consistent with the similar life cycle of these two trematodes which involves amphibious snails (e.g. Lymnaea truncatula) as intermediate hosts, and thus has strong environmental determinants. On the contrary, the lancet fluke D. dendriticum showed low prevalence values $(2.4 \%$ on farms) in the water buffaloes tested, probably due to the more complex life cycle of this fluke, involving earth snails and ants as intermediate hosts.

GI strongyles were the most widespread helminths in the water buffaloes tested $(33.1 \%$ on farms); in addition, they showed a spatial dispersion (lack of clustering), probably due to their life cycle which involves a series of larval stages $\left(\mathrm{L}_{1}-\mathrm{L}_{3}\right)$ in the environment that can develop at different rates depending on the environment. Similar findings of dispersion were also found for Strongyloides spp. showing very low prevalence values on farms $(3.1 \%)$. Finally, a cluster of positive farms was also found for the cestode Moniezia spp. (prevalence $=2.4 \%$ ), probably due to the requirement of oribatid mites to complete its life cycle. 
It is likely that ecological and management factors underlie the spatial distribution of helminths at the water buffalo farms studied and further risk factor analyses are needed. However, few studies focused on the ecological analysis of diseases of water buffaloes are found in the literature. For example, a GIS model for mapping the risk of fasciolosis in buffaloes was developed and validated for the Kingdom of Cambodia using determinants of inundation, proximity to rivers, land use, slope, elevation, and the density of cattle and buffaloes (Tum et al., 2004, 2007). GIS analysis on the transmission of schistosomiasis in water buffaloes were performed in China (Zhou et al., 2000; Wu et al., 2007). Finally, GIS analysis on the transmission of cystic echinococcosis in water buffaloes were performed in southern Italy (Cringoli et al., 2007).

In conclusion, the trends over the past two decades and their effects in the fields of hardware, software and network technology, in particular in the Internet domain, have created the prerequisites for a broad acceptance of GIS within the health sciences, including the veterinary science. The present study demonstrated - once more - that, with the appropriate survey-based data at hand, GIS can be very useful to study the epidemiological patterns of infections in veterinary health, in particular regarding water buffaloes.

\section{References}

Amarjit S, Toshihiko N, 2003. Role of buffalo in the socioeconomic development of rural Asia: current status and future prospectus. Anim Sci J 74, 443-455.

CNIEL (Centre National Interprofessionnel de l'Economie Laitière), 2002. L'economie laitière en chiffres, 183 pp.

Cringoli G, 2006. FLOTAC, a novel apparatus for a multivalent faecal egg count technique. Parassitologia 48, 381-384.

Cringoli G, Guarino A, Fusco G, Merola A, Bani A, 1995.

Endoparasites in buffalo farms from the Caserta province (southern Italy). Bubalus bubalis 4, 55-64.

Cringoli G, Rinaldi L, Musella V, Veneziano V, Maurelli MP, Di Pietro F, Frisiello M, Di Pietro S, 2007. Geo-referencing livestock farms as tool for studying cystic echinococcosis epidemiology in cattle and water buffaloes from southern Italy. Geospat Health 2, 105-111.

Cringoli G, Rinaldi L, Veneziano V, Capelli G, Malone JB, 2002. A cross-sectional coprological survey of liver flukes in cattle and sheep from an area of the southern Italian Apennines. Vet Parasitol 108, 137-143.

Cringoli G, Rinaldi L, Veneziano V, Capelli G, Scala A, 2004. The influence of flotation solution, sample dilution and the choice of McMaster slide area (volume) on the reliability of the McMaster technique in estimating the faecal egg counts of gastrointestinal strongyles and Dicrocoelium dendriticum in sheep. Vet Parasitol 123, 121-131.

Cringoli G, Rinaldi L, Veneziano V, Musella V, 2005. Disease mapping and risk assessment in veterinary parasitology: some case studies. Parassitologia 47, 9-25.

FLOTAC® Manual - Flotac techniques - Herbivores, 2009. Edited by Giuseppe Cringoli. ISBN 978-88-89132-27-2, 80 pp.

Frössling J, Nødtvedt A, Lindberg A, Björkman C, 2008. Spatial analysis of Neospora caninum distribution in dairy cattle from Sweden. Geospat Health 3, 39-45.

Hendrickx G, Biesemans J, de Deken R, 2004. The use of GIS in veterinary parasitology. In: Durr P and Gatrell A (eds.). GIS and Spatial Analysis in Veterinary Science. CABI Publishing, pp. 145-176.

Kulldorff M, 1997. A spatial scan statistic. Commun Stat Theory Methods 26, 1481-1496.

Liu Y, Li F, Liu W, Dai RS, Tan YM, He DS, Lin RQ, Zhu XQ, 2009. Prevalence of helminths in water buffaloes in Hunan province, China. Trop Anim Health Prod 41, 543-546.

Rinaldi L, Musella V, Biggeri A, Cringoli G, 2006. New insights into the application of geographical information systems and remote sensing in veterinary parasitology. Geospat Health 1, 33-47.

Rinaldi L, Musella V, Condoleo R, Saralli G, Veneziano V, Bruni G, Condoleo RU, Cringoli G, 2007. Giardia and Cryptosporidium in water buffaloes (Bubalus bubalis). Parasitol Res 100, 1113-1118.

Rivellini P, Rania U, Urso C, 1972. I nematodi parassiti del tubo intestinale dei bufali allevati nelle province di Latina, Caserta e Salerno - Nota preliminare. Atti SISVet 26, 490-491.

Romano P, Ricciardi A, Salzano G, Suzzi G, 2001. Yeasts from water buffalo mozzarella, a traditional cheese of the 
Mediterranean area. Int J Food Microbiol 69, 45-51.

Thrusfield M, 1995. Veterinary Epidemiology. Blackwell, London, UK, pp. 138-188.

Tum S, Puotinen ML, Copeman DB, 2004. A geographic information systems model for mapping risk of fasciolosis in cattle and buffaloes in Cambodia. Vet Parasitol 122, 141-149.

Tum S, Puotinen ML, Skerratt LF, Chan B, Sothoeun S, 2007. Validation of a geographic information system model for mapping the risk of fasciolosis in cattle and buffaloes in Cambodia. Vet Parasitol 143, 364-367.

Veneziano V, Santaniello M, Carbone S, Pennacchio S, Morgoglione ME, Schioppi M, Condoleo R, Cringoli G,
2007. Lice (Haematopinus tuberculatus) in water buffalo farms from central Italy. IJAS 6, 926-927.

Wu XH, Wang XH, Utzinger J, Yang K, Kristensen TK, Berquist R, Zhao GM, Dang H, Zhou XN, 2007. Spatiotemporal correlation between human and bovine schistosomiasis in China: insight from three national sampling surveys. Geospat Health 2, 75-84.

Zhou X, Sun L, Jiang Q, Guo J, Wang T, Lin D, Yang G, Hong Q, Huang T, Zhang S, Wang Q, Hu F, Guo J, 2000. Geographic information systems spatial analysis on transmission of schistosomiasis in China. Zhonghua Liu Xing Bing Xue Za Zhi 21, 261-263. 